\title{
Behavioral characteristics of children with type-1 diabetes and the effect of family attitudes on dietary adherence problems
}

\author{
Ozlem Onen ${ }^{\oplus}$, Ozlem Nalbantoglu ${ }^{2 \oplus}$, Handan Ozek Erkuran ${ }^{\circledR}$, Sermin Yalin Sapmaz ${ }^{\circledR \oplus}$, Mert Erbas $^{4 \oplus}$, \\ Gulcin $\operatorname{Arslan}^{2}{ }^{\oplus}$, Behzat Ozkan ${ }^{2}$
}

'University of Health Sciences Izmir Dr. Behcet Uz Children's Research and Training Hospital, Department of Child and Adolescent Psychiatry, Izmir - Turkey

2University of Health Sciences Izmir Dr. Behcet Uz Children's Research and Training Hospital, Department of Pediatric Endocrinology, Izmir - Turkey

${ }^{3}$ Celal Bayar University Hospital, Department of Child and Adolescent Psychiatry, Manisa - Turkey

${ }^{4}$ Dokuz Eylul University Hospital, Department of Pediatric Endocrinology, Izmir - Turkey

\begin{abstract}
Objective: Assessing the behavioral characteristics and family attitudes of children and adolescents in diabetes is linked to determining the reasons for difficulties in dietary adherence. Our aim was to assess the relationship between behavioral characteristics, family attitudes in children diagnosed with type 1 diabetes mellitus (T1DM), and the dietary adherence and glycemic control.

Method: Fifty-four patients T1DM patients and 47 controls aged 7-18 years were included in the study together with their parents. Among the patients diagnosed with T1DM followed in the Pediatric Endocrinology Outpatient Clinic, those with high $\mathrm{HbA} 1 \mathrm{c}$ levels (with poor dietary compliance) and those with a HbA1c level below 7.5 (with good dietary compliance) were included in the study as the patient and control group, respectively. A psychiatric assessment interview was conducted with both groups. Sociodemographic data and information on diabetes-related variables, Strengths and Difficulties Questionnaire and Parental Attitude Scale scores were recorded.
\end{abstract}

Results: We have found higher standard diet application rates in patients compared to regular carbohydrate count. The patient group had higher odds of neglecting blood glucose measurement, insulin doses, and a history of stress before decompensation. The rate of psychiatric diagnosis was $26.2 \%$, similar to the general literature, and combined diagnoses were less frequent. Hospital admissions and hypoglycemic episodes were observed at a higher rate in the group that had problems in dietary adherence. Compared to those with good dietary compliance, patients in the dietary non-adherence group had a higher level of parental control and poorer parental perception of their children's peer relationships.

Conclusion: To reduce the risk of acute complications of the disease and to prevent long-term chronic sequelae, it is important to identify positive and some negative behavioral characteristics of child and parental attitudes. Parental role is among the key factors in supporting the autonomy of the child in ensuring dietary compliance.

Keywords: Dietary non-adherence, family function, parental attitude, pediatric type-1 diabetes

How to cite this article: Onen O, Nalbantoglu O, Ozek Erkuran H, Yalin Sapmaz S, Erbas M, Arslan G, Ozkan B. Behavioral characteristics of children with type-1 diabetes and the effect of family attitudes on dietary adherence problems. Dusunen Adam The Journal of Psychiatry and Neurological Sciences 2021;34:73-82.

Correspondence: Ozlem Onen, SBU Izmir Dr. Behcet Uz Children's Research and Training Hospital, Department of Child and Adolescent Psychiatry, 35210, Izmir - Turkey

E-mail: drozlemonen@gmail.com

Received: June 10, 2020; Revised: July 03, 2020; Accepted: December 07, 2020 


\section{INTRODUCTION}

Diabetes mellitus is a chronic metabolic disorder characterized by alteration in glucose, protein, and lipid metabolism due to absolute or relative insulin insufficiency (1).

Type 1 diabetes mellitus (T1DM) accounts for $5-10 \%$ of all diabetes cases worldwide, while $85 \%$ of diabetic patients under the age of 20 have T1DM (2).

Diet is very important in the treatment of diabetes. An individual diet program is prepared for each patient according to their height, weight, physical activity, type of insulin used and dietary habits.

The diet can be divided into two groups as standard diet or carbohydrate count. As part of the standard diet, a diet list that will allow the patient to grow and develop normally is prepared (3). Carbohydrate count is among the most important components of diabetes management and diet (4). Glycosylated hemoglobin (HbAlc), which indicates the mean plasma glucose levels in the last 3 months, is considered a very important biochemical parameter in the evaluation of glycemic control (5). Comorbidities such as dyslipidemia, poor nutritional knowledge, excessive weight gain, and celiac disease require extra education and dietary intervention since they cause changes in the insulin regimen. Dietary education needs to be individualized by taking into account the child's age and maturational learning level. Eating disorders, as well as impaired eating behavior are more common in youth with T1DM compared to their healthy peers (6). Randomized controlled studies have demonstrated that $\mathrm{HbA1c}$ levels decrease with dietary adjustments (7). Of the recommended daily nutritional content, carbohydrates should make up approximately $45-50 \%$ while fats should be $<35 \%$ (unsaturated fat $<10 \%$ ) and protein around $15-20 \%$. Neglecting insulin doses may lead to certain complications such as diabetic ketoacidosis, retinopathy and neuropathy, through causing impairment in glycemic control (6).

Target $\mathrm{HbAlc}$ levels of $7 \%$ are suggested for children, adolescents and young adults under 25 . Meanwhile, for young children who may have problems expressing symptoms of hypoglycemia, who may fail to notice hypoglycemia/severe hypoglycemia history, who are unable to access their analog insulins, and who lack the ability to regularly check and monitor their blood glucose levels, higher levels of $\mathrm{HbA1c}$, such as $7.5 \%$ are recommended to be more appropriate in determining dietary regulation. In general, patients with no history of hypoglycemia, with good quality of life and low levels of care burden, and those in the honeymoon phase can target lower HbA1c levels, such as $6.5 \%$. While $6.5 \%$ is used as a marker for the diagnostic threshold, a target value of $7.5 \%$ is suggested as an appropriate level to determine dietary regulation for children and adolescents (8).

Studies on adaptation to the disease largely ignore the childhood age group, and dietary non-adherence in T1DM becomes one of the most common reasons for hospitalizations and referral to psychiatry units (9-11). Such processes, which are hard to monitor and manage, pose a great risk for the development of psychiatric disorders in diabetics. In addition to age-related developmental difficulties during childhood and adolescence, facing with an extra burden of having a chronic disorder increases the possibility of psychiatric vulnerability $(12,13)$. There are many studies pointing out the presence of psychiatric disorders and behavioral problems in children with diabetes. The most common problem in these children is identified as depressive disorder, followed by anxiety disorders (14) and, although less frequently, behavioral problems (15-17). Psychosocial problems have significant detrimental effects on the physical, psychological and social maturation processes of children as well as their transition to adulthood (14).

It is believed that the assessment of the behavioral characteristics of children and adolescents, as well as family attitudes in diabetes, is linked to determining the reasons for difficulties such patients experience in adhering to diet, and therefore closely related to $\mathrm{HbAlc}$ levels. Beginning in childhood and adolescence, a comprehensive evaluation of psychiatric factors that may affect a patient's dietary adherence can help reduce the risk of long-term complications associated with diabetes. Parental attitudes can support the child's autonomy or hinder their psychiatric development by being overprotective and restrictive. While parental styles to encourage autonomy support children's development as autonomous individuals who adhere to their treatment by helping children fulfill their responsibilities confidently, overprotective parents can promote the opposite traits. It is possible to assess the emotions, behaviors, attention and relationship with others, whether the difficulties affect the daily functioning or the problems in the immediate environment, and the duration of the problems with a detailed psychiatric interview and the use of certain instruments.

The aim of this study is to evaluate the relationship between behavioral characteristics, family attitudes perceived by the child diagnosed with T1DM and non- 
adherence with diet, according to degrees of glycemic control. Determining the behavioral dimension problems of children and child perceptions regarding the parental approach can create the opportunity to work on these issues related to dietary adherence, and in turn, may help promote psychiatric and economic well-being associated with dietary adherence in diabetes, which is a chronic disease that creates both medical and economic burden.

\section{METHOD}

This clinical study was designed as a case-control study. We included volunteers aged 7-18 who were followedup with T1DM between April 2018 and April 2019 in pediatric endocrinology clinics of Dr. Behcet $\mathrm{Uz}$ Children's Hospital and Dokuz Eylul University.

Among the patients with T1DM diagnosis followed up in Pediatric Endocrinology, those with $\mathrm{HbAlc}$ levels above $7.5 \%$ were included in the case group, while the patients with $\mathrm{HbA1c}$ levels below 7.5\% constituted the control group. We planned to include the same number of volunteers in the case and control groups, and the newly diagnosed cases and patients who continued their regular controls in the clinic were recruited. The past psychiatry treatment history, presence of an intellectual disability and autistic spectrum disorder were determined as exclusion criteria for the case and control groups. The required sample size was determined using the G-power program, alpha $=0.05$, power value $=0.80$; and the effect size calculated according to results of the study conducted by Saßmann et al. (18). The required total sample size was found to be 90 individuals; 45 patients and 45 controls. All children and parents who volunteered to participate in the study were interviewed and the scales were completed by the end of this period. In order to determine the existence of psychiatric diagnoses, a DSM-5 based psychiatric assessment interview was applied to the recruited individuals and their behavioral characteristics and family attitudes were evaluated via specific scales and tools. Data collected from both groups were compared. Data including the age of children, whether there are siblings or parents in the family diagnosed with diabetes, the age at which diabetes was diagnosed, average daily insulin doses, diet types, concurrent autoimmune or any other medical problem, previous diagnosis of a psychiatric disorder, current diagnosis following psychiatric evaluation, history of hospitalization due to diabetes, ketoacidosis and hypoglycemia, failure to measure blood glucose or insulin injections were recorded.

In our multi-centered case-control study, the behavioral characteristics of the children were evaluated using the Strengths and Difficulties Questionnaire (SDQ) and the parental attitude using the Parental Attitude Scale (PAS). While the PAS was filled by the child, the SDQ forms were filled out by both the children and the parents.

Informed consent was obtained from all participants for this study. This study was approved by the local ethics committee for clinical researches of the hospital where the study was conducted (approval number: 2018/04-07).

\section{Measures}

Strengths and Difficulties Questionnaire (SDQ): Used to screen mental problems in children and young people, this scale was developed by Goodman et al. (19). It provides an assessment of social, emotional and behavioral functioning. The questionnaire includes the parent form and teacher form for 4-16 year-olds, the adolescent form and parent forms for those between 11-16 years old. The SDQ consists of 25 questions in total, with some items assess positive and some negative behavioral characteristics. These questions are grouped under 5 subtitles. These subtitles are; behavioral problems, attention deficit and hyperactivity, emotional problems, peer problems and social behavior. While being assessed under each title separately, the sum of the first four titles (emotional symptoms, behavioral problems, hyperactivity-distraction and peer relationship scores) gives the 'total difficulty score'. High scores on all measures except prosocial behavior are associated with worsening of symptoms. The Turkish validity and reliability of the scale were carried out by Guvenir et al. (20); and later Yalin et al. (21) further developed the tool for advanced psychometric properties.

Parent Attitude Scale (PAS): The tool, originally called the Parent Attitude Scale, was developed in 1991 to measure parental attitudes (22). The scale has 3 subdimensions: control/supervision, acceptance/interest, and gaining psychological autonomy, consisting of 26 items and can be applied to adolescents. The Turkish validity and reliability study was conducted by Yilmaz (23) as the "Parenting Attitude Scale".

\section{Statistical Analysis}

Statistical Package for Social Sciences Program for Windows 20.0 version (SPSS, 20.0) was used in this study. To compare groups, the chi-square test was used for categorical variables, and Student's t-test for 
continuous variables., Student's t-test was used for variables with normal distribution, while the chi-square test was used for qualitative data in comparison of independent groups. Statistical significance level was determined at $\mathrm{p}<0.05$. Kolmogorov-Smirnov test was used to determine whether the parameters were in accordance with normal distribution. Results were presented as mean \pm standard deviation.

\section{RESULTS}

\section{Sample Features}

The required sample size was determined using the G-power program and found to be 90 individuals; 45 patients and 45 controls. The duration of the study was extended since we could not reach the required sample size within the specified period. The study was finalized with the participation of 54 patients and 47 controls.

Patient and control groups were compared by age, gender distribution and time elapsed since diabetes onset. There was no statistically significant difference between the patient and control groups in terms of gender and age. All children and adolescents included in the study were between the ages of 8-17 (13.1 \pm 2.4$)$. The time elapsed since the onset of diabetes ranged from 1 to 6 years $(4.6 \pm 2.8)(\mathrm{p}>0.05)$ and no significant difference was found between good and poor dietary adherence groups, regarding the duration of the diabetes diagnosis. There was no significant difference between the groups in terms of the effect of disease duration on the diagnosis or scale scores ( $p>0.05$ ).

Diet characteristics were evaluated and compared between good and poor dietary adherence groups since HbAlc levels are known to be closely related to the diet type. There was a statistically significant difference in terms of diet types. While the standard diet was used more frequently in the patient group, the control group with good dietary adherence preferred regular carbohydrate count $(\mathrm{p}=0.011)$.
Hashimoto's thyroiditis and celiac disease are autoimmune based conditions that require an additional diet plan. Apart from the diet plan that T1DM would require, the need to increase another diet plan for additional health conditions or treatment for other non-autoimmune diseases can place an extra burden on affected individuals. In terms of comorbid disease (5.6\% of the patient group, $2.1 \%$ of the control group) and comorbid autoimmune disease (13\% of the patient group, $6.4 \%$ of the control group), there was no statistically significant difference between the two groups ( $\mathrm{p}>0.05$ ). In total, only 4 (4\%) out of 101 patients received diet for comorbid autoimmune diseases. Of the four individuals, 3 were in the case group, while one was in the control group. According to psychiatric evaluation interviews of the patients and controls, the distribution of diagnoses of those diagnosed with any psychiatric disorder was determined (Table 1). Of the patient group, $35,2 \%(n=19)$ and $17 \%(n=8)$ of the control group were diagnosed with a psychiatric disorder after the psychiatric evaluation interview.

The distribution of independent variables such as time of DM diagnosis, number of inpatients for T1DM, history of ketoacidosis, history of hypoglycemia, daily mean insulin doses, and HbAlc level were analyzed between two groups. A comparison of the two groups in terms of T1DM related variables was presented (Table 2).

Independent variables, including blood glucose measurement neglect, insulin dose neglect, and stressors history were found to be the most significant factors that have an impact on $\mathrm{HbAlc}$ regulation and were more common in the patient group than in controls (Table 3).

As an independent variable, the effect of mental impairment on dependent variables, including insulin dose neglect and blood glucose measurement neglect was also significant. Insulin dose neglect was found in 8 (30.8\%) of 27 patients diagnosed with a psychiatric disorder, and blood glucose measurement negligence

Table 1: Rates of psychiatric disorders

Diagnosis

Depressive disorder
Anxiety disorder
Depressive disorder+ADHD
Depressive disorder+conduct disorder
Tic disorder
Total

Poor glycemic control

n (\%)

$15(27.8)$

3 (5.6)

$1(1.8)$

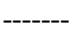

Good glycemic control

n (\%)

$4(8.5)$

1 (2.1)

1 (2.1)

$1(2.1)$

$1(2.1)$

$47(100)$

ADHD: Attention deficit hyperactivity disorder 
Table 2: Comparison of the two groups by diabetes-related variables

\begin{tabular}{|c|c|c|c|c|c|c|c|}
\hline & \multicolumn{2}{|c|}{$\begin{array}{l}\text { Poor glycemic } \\
\text { control }\end{array}$} & \multicolumn{2}{|c|}{$\begin{array}{l}\text { Good glycemic } \\
\text { control }\end{array}$} & \multirow[b]{2}{*}{$\mathbf{t}$} & \multirow[b]{2}{*}{ df } & \multirow[b]{2}{*}{$\mathbf{p}$} \\
\hline & Mean & SD & Mean & SD & & & \\
\hline Time of T1DM diagnosis & 4.82 & 2.93 & 4.02 & 2.61 & 1.44 & 99 & 0.152 \\
\hline Number of inpatient for T1DM & 1.69 & 1.22 & 1.26 & 0.67 & 2.21 & 84.5 & 0.029 \\
\hline History of ketoacidosis & 1.30 & 1.35 & 0.94 & 0.63 & 1.74 & 77.7 & 0.085 \\
\hline History of hypoglycemia & 3.48 & 5.38 & 1.26 & 2.39 & 2.73 & 75.7 & 0.008 \\
\hline Daily mean insulin doses & 0.96 & 0.34 & 0.94 & 0.31 & 0.17 & 86 & 0.865 \\
\hline HbA1c level & 9.21 & 1.80 & 7.04 & 0.71 & 8.11 & 71.3 & 0.000 \\
\hline
\end{tabular}

df: Degrees of freedom, SD: Standard deviation, T1DM: Type 1 diabetes mellitus

Table 3: Data on failure to measure blood sugar, skipping insulin doses and the presence of previous stressors

\begin{tabular}{|c|c|c|c|c|c|c|c|}
\hline & \multicolumn{2}{|c|}{ Yes } & \multicolumn{2}{|c|}{ No } & \multirow[b]{2}{*}{$\chi^{2}$} & \multirow[b]{2}{*}{ df } & \multirow[b]{2}{*}{$\mathbf{p}$} \\
\hline & Patient (\%) & Control (\%) & Patient (\%) & Control (\%) & & & \\
\hline Failure to measure blood sugar & $17(31.5)$ & $2(4.3)$ & $37(68.5)$ & $45(95.7)$ & 12.1 & 1 & $<0.001$ \\
\hline Skipping insulin doses & $15(27.8)$ & $1(2.1)$ & $39(72.2)$ & $46(97.9)$ & 12.4 & 1 & $<0.001$ \\
\hline Presence of stressors & $16(29.6)$ & $1(2.1)$ & $38(70.4)$ & 46 (97.9) & 13.5 & 1 & $<0.001$ \\
\hline
\end{tabular}

df: degree of freedom, $\chi^{2}$ : Chi-square value

was positive in 11 patients $(42.3 \%)(\mathrm{p}<0.001)$. When other individuals, family and disease-related characteristics were evaluated, no statistically significant difference was found between the groups in terms of independent variables of having a diagnosis of diabetes in a parent or sibling, a diagnosis of a psychiatric disorder, or a history of a previous admission to a psychiatric outpatient unit ( $p>0.05)$. Any history of psychiatric diagnosis that was positive before the enrollment in the study was $10.9 \%$ (6 patients and 5 controls). Logistic Regression Analyses:

The mean PAS and SDQ scores of both groups were calculated (Table 4). The patient group had higher supervision dimension scores in PAS than those with good dietary adherence $(p=0.012)$. In the group with dietary incompliance, the mean parent-peer relationship subscale of the SDQ was higher than those with good dietary compliance $(\mathrm{p}=0.039)$.

Table 4: Comparison of PAS and SDQ scores

\begin{tabular}{|c|c|c|c|c|c|}
\hline & \multicolumn{2}{|c|}{ Case } & \multicolumn{2}{|c|}{ Control } & \multirow[b]{2}{*}{ t value } \\
\hline & Mean & SD & Mean & SD & \\
\hline PAS Acceptance/Involvement dimension & 28.78 & 4.23 & 28.87 & 5.70 & -0.09 \\
\hline PAS psychological autonomy dimension & 24.56 & 5.05 & 24.19 & 6.89 & 0.30 \\
\hline PAS supervision dimension & 29.13 & 4.24 & 26.00 & 7.30 & 2.58 \\
\hline SDQ child emotion dimension & 2.42 & 2.13 & 2.23 & 2.37 & 0.42 \\
\hline SDQ child behavior dimension & 2.03 & 1.72 & 1.74 & 1.84 & 0.82 \\
\hline SDQ child hyperactivity attention deficiency & 3.00 & 2.18 & 3.29 & 2.44 & -0.64 \\
\hline SDQ child peer relationships & 2.35 & 1.73 & 1.95 & 1.42 & 1.23 \\
\hline SDQ child prosocial dimension & 8.27 & 1.52 & 7.85 & 2.71 & 0.95 \\
\hline SDQ parent emotional dimension & 2.96 & 2.30 & 2.38 & 1.96 & 1.35 \\
\hline SDQ parent behavior dimension & 1.94 & 1.86 & 1.53 & 1.50 & 1.21 \\
\hline SDQ parent hyperactivity attention deficiency & 3.35 & 2.59 & 2.74 & 2.25 & 1.24 \\
\hline SDQ parent peer relationships & 2.74 & 1.79 & 1.95 & 1.25 & 2.57 \\
\hline SDQ parent prosocial dimension & 7.81 & 2.31 & 8.21 & 2.21 & -0.87 \\
\hline
\end{tabular}

PAS: Parental Attitude Scale, SDQ: Strengths and Difficulties Questionnaire, df: Degrees of freedom, SD: Standard deviation 
Table 5: Multiple logistic regression analysis to determine the effect of PAS and SDQ results on being patient

\begin{tabular}{lcccccc} 
Variable & B & SE & p & df & Odds ratio & $\mathbf{9 5 \%} \mathbf{C l}$ \\
\hline PAS supervision dimension & -0.97 & 0.039 & 0.014 & 1 & 0.090 & $0.84-0.98$ \\
Constant & 2.54 & 1.11 & 0.023 & 1 & 12.75 & \\
\hline
\end{tabular}

PAS: Parental Attitude Scale, SDQ: Strengths and Difficulties Questionnaire, df: degree of freedom, SE: Standart error, Cl: Confidence interval, B: unstandardized B regression coefficient

Multiple logistic regression analysis was performed to determine the effect of PAS and SDQ results on being a patient (Table 5). The impact of PAS and SDQ scores as independent variables on being a patient or a control as a dependent variable was evaluated and it was observed that the most important sub-scale values of both tests were the scores of the supervision dimension of the PAS scale $(B=0.09 ; \mathrm{p}=0.01)$.

\section{DISCUSSION}

This study aimed to assess the demographic characteristics of T1DM patients with dietary nonadherence and good dietary compliance according to their $\mathrm{HbAlc}$ levels. In addition, the differences between parental attitudes and children's behavioral characteristics were compared between the two groups. It was found that the group with good dietary compliance had significantly higher carbohydrate counts. The number of hospitalizations and the frequency of hypoglycemic attacks were higher in the group with poor dietary adherence than those with good diet compliance.

In terms of parental attitudes, while the only area that differed between groups with poor and good dietary compliance was the control dimension, it was observed that the views of parents on their children's behavior were particularly negative in terms of peer relationships.

Additional dietary requirements due to comorbid medical conditions along with diabetes may adversely affect HBAlc levels through creating different consequences in both the child's behavioral characteristics and parental attitudes. The low rates of children and adolescents who required additional diet due to their comorbid autoimmune conditions in our study sample might have caused indifference in the statistical analyses. Studies on larger samples, including patients requiring additional diet are likely to yield different results regarding the effect of such conditions on HBA1c. The psychiatric disorders rates found were consistent with those in the general literature. In terms of diabetes-related variables, the number of hospitalizations, number of hypoglycemic episodes, blood glucose measurement neglect, neglect of insulin doses, and stress factors were observed to be more common in the group whose dietary compliance was impaired. The effect of the psychiatric impairment on insulin dose and blood glucose measurement neglect was also significant. Moore et al. (24) have reported that parents who perceive that their children neglect of their self-care routines tend to be more anxious and may fail to perform positive parenting skills to a lesser extent. Such interactions can increase oppositional behavior in children and ultimately lead to a much more serious self-care neglect, with an increase in HbAlc levels. By not being able to provide the child an opportunity to take responsibility for the diagnosis of T1DM, overprotective parental attitudes may cause the child to become more dependent on the parent. (24). Williams et al. (25) have suggested that the treatment of noncompliance in children affected their psychiatric wellbeing, self-assurance and the adjustment of the child and/or adolescent through creating an incline in the levels of parental anxiety and stress levels.

The onset of diabetes for our participants varied between less than 1 to 12 years (mean: $4.6 \pm 2.8$ ), and no significant difference was found between the groups regarding diabetes onset in neither the diagnosis nor scale scores. Cho et al. (2013) reported a positive correlation between duration of disease and depressive symptoms of patients, and higher depression scale scores and $\mathrm{HbAlc}$ levels in patients diagnosed with diabetes for more than a year $(26,27)$. A comprehensive evaluation of diabetic patient samples that differ at the onset of the disease, despite being treated with similar treatment approaches may yield further findings on the effects of relevant psychic processes. The unexpected complications of T1DM, a life-long disease, may be a direct factor in the development of a psychiatric disorder Determining the effects of such variables at the onset of a new diagnosis as well as at the beginning of the adaptation process can help children and their families prepare a guideline for future studies. Studies on psychiatric problems in adolescents and young adults with T1DM report different rates for the observed disorders, such as 33\% (28), 36\% (29), 47.6\% (30), 26.2\% (31) and in a study conducted in our 
country $68 \%$ (32). In our study, psychiatric disorders were observed in $26.2 \%$ of the whole sample, and considering the size of the group evaluated, the results were consistent with those reported in the literature. We found that the most common psychiatric disorder was Depressive Disorder, followed by Anxiety Disorder (14); and to a lesser extent, behavioral problems, as described in the relevant literature (15-17). In addition, attention deficit hyperactivity disorder (ADHD) and tic disorder were among other diagnoses. Problems in peer relationships, stigmatization, differences in ethnic and religious perspectives can create a burden for patients with T1DM and their parents (26). The reluctance of children and adolescents to adapt their feeding and insulin hours into school life due to the fear of stigmatization may cause a neglect of treatment as well as the emergence of other comorbid psychiatric problems. Muslu et al. (33) reported that the main issues that the patients go through involved coping styles, feeling challenged, learned hopelessness, pressure from the social environment, personality structure, hiding, defiance, feelings, frustration and a tendency to ignore in the initial adaptation phase to T1DM, which is a lifetime chronic medical condition that also bears psychiatric and psychosocial consequences. Psychiatric well-being is affected by all these processes and in the meantime, it affects all the processes as well. Challenges in adapting to the T1DM diagnosis, failure to address challenges in parent-child interaction and for the child himself/herself, treatment burden and other problems of adolescence may all adversely affect mental health. When patients with comorbid diagnoses were included, the prevalence of depressive disorder increased to $80.7 \%$ from $73.1 \%$. The estimated prevalence of depression in children and adolescents with T1DM was $11.2 \%$ higher than reported in healthy young people (34). In the study of Cho et al. (27) the prevalence of depression in children and adolescents with T1DM was reported to be $20 \%$. In the study of Sahin et al. (32) adjustment disorder, anxiety disorders, depressive disorder, ADHD and ODD, conduct disorder were among the diagnosed psychiatric disorders. In our study, contrary to the results obtained from other researches $(35,36)$, indicating that the rates of multiple psychiatric diagnoses were high, combined diagnoses were found to be less frequent.

T1DM management is complex and requires the ability to cope with lifestyle changes (dietary restrictions, regular blood sugar measurements) and maintenance of a regular daily treatment (37). When young individuals fail to handle physical, cognitive and psychological changes and become more vulnerable, mental health problems also accompany the process $(38,39)$. Evidence shows that compliance to the diabetes self-care system is partially poor in adolescents (40). As a part of the normal development process of adolescents, changes and pressure due to a chronic disorder, problems involving self-awareness, restraint compliance and regularity may occur, and this tension can create a medium for the occurrence of psychiatric disorders by creating stress for the individual and family (41). In our study, it was found that the effects of blood glucose measurement neglect, insulin dose neglect and stress factor in developing a psychiatric diagnosis were significant. On the other hand, psychiatric disorders have also been found to cause neglect and stress. In our study, no significant difference was found between the two groups in terms of acceptance interest and psychological autonomy sub-dimensions of PAS, whereas the children in the psychiatric diagnosis group perceived their parents as more supervisory. The logistic regression analysis results also pointed out that the most significant factor in being a patient with blood glucose disorder is the supervision dimension. The parents of a child with a chronic disease are often reported to have concerns about their children's neglect their daily diets or self-care routines, and conduct a lifestyle in which they can endanger their blood glucose/ insulin management (42). Parents are often unable to directly observe their child's self-care activities, and may tend to be more involved in the adolescent's diabetes management processes until they feel fully confident, while the adolescent's privacy is at risk of being harmed. This intense anxiety experienced by the parents may also increase e family conflict $(43,44)$. Parents can be overly accusatory, overprotective and intrusive (45). In this case, it becomes more difficult for the child to manage the disease process. In the study of Wilson et al. (46) dietary noncompliance and mealtime behavioral problems of young children with T1DM were found to be associated with parental over-control and disciplinary behavior. Weinger et al. (47) found that even routine activities (e.g. driving) caused anxiety and negative emotional expressions towards the child in mothers of adolescents with T1DM. In the same study, adolescents stated that their mothers sometimes unfairly blamed them for the interruptions in the management of the disease. In another study, adolescents with T1DM also stated that their mothers displayed overprotective and accusatory behaviors due to similar concerns (related to the competence of the adolescent in managing diabetes) (48). Faulkner and 
Chang (49) reported that adolescents who had a warm and positive relationship with their parents were more successful in performing their self-care routines, were less concerned about diabetes, and were more satisfied with their lives. An emotionally supportive and accepting parenting style (sensitive, accessible) would provide continuous improvement in the life quality of children and young people with T1DM (43). In their qualitative study involving the parents of 40 patients with T1DM, Dashiff et al. (50) found that caregivers experienced anxiety and frustration regarding their ongoing parenting roles. In a study by Geffken et al. (51) conducted with 100 adolescents aged 7-18 years, with and without diabetic ketoacidosis; families with warm, positive and accepting interactions were found to have lower rates of ketoacidosis in their children. The impact of PAS and SDQ scores as independent variables on the dependent variables of being in the patient or the control group was assessed and the supervision dimension scores of the PAS scale was found to be the most significant among all subscales of both tests.

When SDQ forms and behavioral characteristics of children were examined, no significant difference was found between the two groups, however a significant difference existed in terms of the parental descriptions of their children's peer relationships. Parents of children with T1DM and dietary non-compliance, have reported more peer problems for their children. Schafer et al. (52) reported poor metabolic control in adolescents with more negative interactions with family members. High levels of relationship difficulties and lower blood glucose level monitoring have been highly associated with dietary non-compliance (53). Although no differences were observed in the children's peer relationship subscale scores, the negative scores for peer relationships of their children in the diet noncompliance group of the parents may be associated with the possible high anxiety levels and the low tendency to provide autonomy to their children.

Since this study is single-centered, the findings cannot be generalized to the whole population. The heterogeneous features of the parents, the difference between the time elapsed after the diagnosis of T1DM, and the recall and/or biases of the children regarding their past psychiatric histories or stressors were among the limitations of the study. T1DM may also have different effects on different age groups in SDQ. Therefore, studies with larger samples are needed. The lower rates of comorbid conditions in childhood T1DM and complications due to polyneuropathy may also have contributed to the indifference of the subscale scores between the good dietary compliance and the non-compliance groups. Although there are different studies on T1DM that have used SDQ and PAS in the literature, this is the first study that uses both scales in Turkey. We believe that it is an important study in terms of associating psychiatric disorders and HbAlc level and therefore showing dietary compliance in T1DM, despite all its limitations.

T1DM is a challenging chronic disease for children and their families since it requires compulsory treatment and creates many psychosocial difficulties. Many factors are responsible for the reduction of individuals' adaptive behaviors in the management of the disease, such as an increased adolescent desire for autonomy and independence, blood sugar measurements and perception problems caused by repetitive interventions to the body through insulin administration, and the accompanying mental health disorders in the process. Despite all the challenges, it is necessary to aim to achieve results with less vascular complications and a healthier life in adulthood with optimal glycemic control. Therefore, it is important to identify adaptive individual and familial factors to T1DM.

It is thought that the role of the parent in promoting autonomy in diabetes management may help the child to have better trust and greater control over his/her responsibilities to keep glycemic control at an ideal level.

In order to reduce the risk of acute and chronic complications of the disease, it is important to identify individual and familial factors such as family structure, social environment, treatment adherence, peer relationships, quality of life, and mental well-being requirements that ensure compatibility with T1DM. Parental role is among the key factors in supporting the autonomy of the child in ensuring compliance with the diet.

\begin{tabular}{|l|l|l|}
\hline \multicolumn{4}{|l|}{ Contribution Categories } & Author Initials \\
\hline \multirow{4}{*}{ Category 1} & Concept/Design & O.O \\
\cline { 2 - 3 } & Data acquisition & $\begin{array}{l}\text { O.O, H.O.E, O.N, G.A, B.O, } \\
\text { M.E }\end{array}$ \\
\cline { 2 - 3 } & Data analysis/Interpretation & O.O, G.A, M,E \\
\hline \multirow{3}{*}{ Category 2} & Drafting manuscript & O.O, S.Y.S., H.O.E, O.N \\
\cline { 2 - 3 } & Critical revision of manuscript & O.O, M.E, H.O.E, S.Y.S \\
\hline \multirow{2}{*}{ Category 3} & Final approval and accountability & O.O, G.A, H.O.E \\
\hline \multirow{3}{*}{ Other } & Technical or material support & O.O, H.O.E \\
\cline { 2 - 3 } & Supervision & O.O, O.N, S.Y.S, B.O \\
\hline
\end{tabular}

Ethics Committee Approval: This study was approved by the Behçet Uz Training and Research Hospital Ethics Committee (Date: 22.02.2018, Approval number: 2018/04-07). 
Informed Consent: Informed consent was obtained from all participants for this study.

Peer-review: Externally peer-reviewed.

Conflict of Interest: The authors would like to declare no conflict of interest.

Financial Disclosure: This paper was not supported by any grant or fellowship.

\section{REFERENCES}

1. The Society of Endocrinology and Metabolism of Turkey. Clinical Practice Guideline for Diagnosis, Treatment and Followup of Diabetes Mellitus and Its Complications-2019. http://temd. org.tr/admin/uploads/tbl_kilavuz/20191107144832-2019tbl_ kilavuz7c65cb4e70.pdf. Accessed: July 07, 2019 (Turkish)

2. SEARCH for Diabetes in Youth Study Group, Liese AD, D’Agostino RB Jr, Hamman RF, Kilgo PD, Lawrence JM, et al. The burden of diabetes mellitus among US youth: prevalence estimates from the SEARCH for Diabetes in Youth Study. Pediatrics 2006; 118:1510-1518.

3. Levin L, Ban Y, Concepcion E, Davies TF, Greenberg DA, Tomer Y. Analysis of HLA genes in families with autoimmune diabetes and thyroiditis. Hum Immunol 2004; 65:640-647.

4. Mehta SN, Quinn N, Volkening LK, Laffel LM. Impact of carbohydrate counting on glycemic control in children with type 1 diabetes. Diabetes Care 2009; 32:1014-1016.

5. American Diabetes Association. 11. Children and Adolescents. Diabetes Care 2016; 39(Suppl.1):S86-93.

6. Smart CE, Annan F, Higgins LA, Jelleryd E, Lopez M, Acerini CL. ISPAD Clinical Practice Consensus Guidelines 2018: Nutritional management in children and adolescents with diabetes. Pediatr Diabetes 2018; 19(Suppl.27):136-154.

7. Canadian Diabetes Association Clinical Practice Guidelines Expert Committee, Dworatzek PD, Arcudi K, Gougeon R, Husein N, Sievenpiper JL, Williams SL. Nutrition therapy. Can J Diabetes 2013; 37(Suppl.1):S45-55.

8. DiMeglio LA, Acerini CL, Codner E, Craig ME, Hofer SE, Pillay $\mathrm{K}$, et al. ISPAD Clinical Practice Consensus Guidelines 2018: Glycemic control targets and glucose monitoring for children, adolescents, and young adults with diabetes. Pediatr Diabetes 2018; 19(Suppl.27):105-114.

9. Karvonen M, Viik-Kajander M, Moltchanova E, Libman I, LaPorte R, Tuomilehto J. Incidence of childhood type 1 diabetes worldwide. Diabetes Mondiale (DiaMond) Project Group. Diabetes Care 2000; 23:1516-1526.

10. DiMatteo MR, Lepper HS, Croghan TW. Depression is a risk factor for noncompliance with medical treatment: meta-analysis of the effects of anxiety and depression on patient adherence. Arch Intern Med 2000; 160:2101-2107.

11. Riekert KA, Drotar D. Who participates in research on adherence to treatment in insulin-dependent diabetes mellitus? Implications and recommendations for research. J Pediatr Psychol 1999; 24:253-258.
12. Hysing M, Elgen I, Gillberg C, Lie SA, Lundervold AJ. Chronic physical illness and mental health in children. Results from a large-scale population study. J Child Psychol Psychiatry 2007; 48:785-792.

13. Pinquart $M$, Shen Y. Depressive symptoms in children and adolescents with chronic physical illness: an updated metaanalysis. J Pediatr Psychol 2011; 36:375-384.

14. Dantzer C, Swendsen J, Maurice-Tison S, Salamon R. Anxiety and depression in juvenile diabetes: a critical review. Clin Psychol Rev 2003; 23:787-800.

15. Northam EA, Matthews LK, Anderson PJ, Cameron FJ, Werther GA. Psychiatric morbidity and health outcome in Type 1 diabetes-perspectives from a prospective longitudinal study. Diabet Med 2005; 22:152-157.

16. Leonard BJ, Jang YP, Savik K, Plumbo PM, Christensen R. Psychosocial factors associated with levels of metabolic control in youth with type 1 diabetes. J Pediatr Nurs 2002; 17:28-37.

17. Akbas S, Karabekiroglu K, Ozgen T, Tasdemir G, Karakurt M, Senses A, et al. Association between emotional and behavioral problems and metabolic control in children and adolescents with Type 1 diabetes. J Endocrinol Invest 2009; 32:325-329.

18. Sassmann H, de Hair M, Danne T, Lange K. Reducing stress and supporting positive relations in families of young children with type 1 diabetes: a randomized controlled study for evaluating the effects of the DELFIN parenting program. BMC Pediatr 2012; 12:152.

19. Goodman R, Meltzer H, Bailey V. The Strengths and Difficulties Questionnaire: a pilot study on the validity of the self-report version. Int Rev Psychiatry 2003; 15:173-177.

20. Guvenir T, Ozbek A, Baykara B, Arkar H, Sentürk B, Incekas S. Psychometric properties of the turkish version of the Strengths And Difficulties Questionnaire (SDQ-TUR). Turk J Child Adolesc Ment Health 2008; 15:65-74. (Turkish)

21. Yalın S, Ozbek A, Guvenir T, Baydur H. The advanced psychometric properties of turkish Strengths And Difficulties Questionnaire (SDQ). Turk J Child Adolesc Ment Health 2013; 20:23-32. (Turkish)

22. Lamborn SD, Mounts NS, Steinberg L, Dornbusch SM. Patterns of competence and adjustment among adolescents from authoritative, authoritarian, indulgent, and neglectful families. Child Dev 1991; 62:1049-1065.

23. Yilmaz A. Parenting style scale: reliability and validity. Turk J Child Adolesc Ment Health 2000; 7:160-172. (Turkish)

24. Moore SM, Hackworth NJ, Hamilton VE, Northam EP, Cameron FJ. Adolescents with type 1 diabetes: parental perceptions of child health and family functioning and their relationship to adolescent metabolic control. Health Qual Life Outcomes 2013; 11:50.

25. Williams LB, Laffel LM, Hood KK. Diabetes-specific family conflict and psychological distress in paediatric Type 1 diabetes. Diabet Med 2009; 26:908-914.

26. Bratina N, Forsander G, Annan F, Wysocki T, Pierce J, Calliari LE, et al. ISPAD Clinical Practice Consensus Guidelines 2018: Management and support of children and adolescents with type 1 diabetes in school. Pediatr Diabetes 2018; 19(Suppl.27):287-301. 
27. Cho E, Shin SH, Eun SH, Kim JY, Nam HK, Lee KH, et al. Psychological characteristics of Korean children and adolescents with type 1 diabetes mellitus. Ann Pediatr Endocrinol Metab 2013; 18:122-127.

28. Blanz BJ, Rensch-Riemann BS, Fritz-Sigmund DI, Schmidt MH. IDDM is a risk factor for adolescent psychiatric disorders. Diabetes Care 1993; 16:1579-1587.

29. Kovacs M, Ho V, Pollock MH. Criterion and predictive validity of the diagnosis of adjustment disorder: a prospective study of youths with new-onset insulin-dependent diabetes mellitus. Am J Psychiatry 1995; 152:523-528.

30. Kovacs M, Goldston D, Obrosky DS, Bonar LK. Psychiatric disorders in youths with IDDM: rates and risk factors. Diabetes Care 1997; 20:36-44.

31. Block WM, Putzer GJ, Jaramillo JR. Children with type 2 diabetes mellitus and the prevalence of psychiatric disorders. South Med J 2010; 103:1214-1218

32. Sahin N, Oztop DB, Yilmaz S, Altun H. Assessment of Psychopathology, Quality of Life, and Parental Attitudes in Adolescents with Type 1 Diabetes Mellitus. Noro Psikiyatr Ars 2015; 52:133-138.

33. Muslu L, Ardahan M, Gunbayi I. Perceptions of patients with type 2 diabetes mellitus on psychosocial adaptation process: a phenomenological study. Current Approaches in Psychiatry 2017; 9:75-100. (Turkish)

34. Merikangas KR, He JP, Burstein M, Swanson SA, Avenevoli $S$, Cui L, et al. Lifetime prevalence of mental disorders in U.S. adolescents: results from the National Comorbidity Survey Replication--Adolescent Supplement (NCS-A). J Am Acad Child Adolesc Psychiatry 2010; 49:980-989.

35. Goldston DB, Kelley AE, Reboussin DM, Daniel SS, Smith JA, Schwartz RP, et al. Suicidal ideation and behavior and noncompliance with the medical regimen among diabetic adolescents. J Am Acad Child Adolesc Psychiatry 1997; 36:15281536.

36. Northam EA, Matthews LK, Anderson PJ, Cameron FJ, Werther GA. Psychiatric morbidity and health outcome in Type 1 diabetes-perspectives from a prospective longitudinal study. Diabet Med 2005; 22:152-157.

37. Cummins E, Royle P, Snaith A, Greene A, Robertson L, McIntyre $\mathrm{L}$, et al. Clinical effectiveness and cost-effectiveness of continuous subcutaneous insulin infusion for diabetes: systematic review and economic evaluation. Health Technol Assess 2010; 14:1-181.

38. Northam EA, Lin A, Finch S, Werther GA, Cameron FJ. Psychosocial well-being and functional outcomes in youth with type 1 diabetes 12 years after disease onset. Diabetes Care 2010; 33:1430-1437.

39. Scaramuzza A, De Palma A, Mameli C, Spiri D, Santoro L, Zuccotti GV. Adolescents with type 1 diabetes and risky behaviour. Acta Paediatr 2010; 99:1237-1241.
40. Stewart SM, Emslie GJ, Klein D, Haus S, White P. Self-care and glycemic control in adolescents with Type 1 diabetes. Children's Health Care 2005; 34:239-244.

41. Cameron FJ, Clarke C, Hesketh K, White EL, Boyce DF, Dalton VL, et al. Regional and urban Victorian diabetic youth: clinical and quality-of-life outcomes. J Paediatr Child Health 2002; 38:593-596.

42. Streisand R, Mackey ER, Elliot BM, Mednick L, Slaughter IM, Turek J, et al. Parental anxiety and depression associated with caring for a child newly diagnosed with type 1 diabetes: opportunities for education and counseling. Patient Educ Couns 2008; 73:333-338

43. Botello-Harbaum M, Nansel T, Haynie DL, Iannotti RJ, SimonsMorton B. Responsive parenting is associated with improved type 1 diabetes-related quality of life. Child Care Health Dev 2008; 34:675-681.

44. Drew LM, Berg C, King P, Verdant C, Griffith K, Butler J, et al. Depleted parental psychological resources as mediators of the association of income with adherence and metabolic control. J Fam Psychol 2011; 25:751-758.

45. Marshall M, Carter B, Rose K, Brotherton A. Living with type 1 diabetes: perceptions of children and their parents. J Clin Nurs 2009; 18:1703-1710.

46. Wilson AC, DeCourcey WM, Freeman KA. The impact of managing school-aged children's diabetes: the role of child behavior problems and parental discipline strategies. J Clin Psychol Med Settings 2009; 16:216-222.

47. Weinger K, O’Donnell AK, Ritholz MD. Adolescent views of diabetes related parent conflict and support: A focus group analysis. J Adolesc Health 2001; 29:330-336.

48. Carroll AE, Marrero DG. How do parents perceive their adolescent's diabetes: a qualitative study. Diabet Med 2006; 23:1222-1224.

49. Faulkner MS, Chang LI. Family influence on self-care, quality of life, and metabolic control in school-age children and adolescents with type 1 diabetes. J Pediatr Nurs 2007 ;22:59-68.

50. Dashiff C, Riley BH, Abdullatif H, Moreland E. Parents' experiences supporting self-management of middle adolescents with type 1 diabetes mellitus. Pediatr Nurs 2011; 37:304-310.

51. Geffken GR, Heather L, Walker KN, Storch EA, Heidgerken $\mathrm{AD}$, Lewin A, et al. Family functioning processes and diabetic ketoacidosis in youths with type I diabetes. Rehabilitation Psychology 2008; 53:231-232.

52. Schafer LC, McCaul KD, Glasgow RE. Supportive and nonsupportive family behaviors: relationships to adherence and metabolic control in persons with type I diabetes. Diabetes Care 1986; 9:179-185.

53. Chisholm V, Atkinson L, Donaldson C, Noyes K, Payne A, Kelnar C. Predictors of treatment adherence in young children with type 1 diabetes. J Adv Nurs 2007; 57:482-493. 